Research Article

\title{
Association of the TCF7L2 rs12255372 (G/T) variant with type 2 diabetes mellitus in an Iranian population
}

Faranak Mahmoudi Alami ${ }^{1}$, Mehran Ahmadi $^{2}$, Hamidreza Bazrafshan ${ }^{3}$, Alijan Tabarraei ${ }^{4}$, Ayyoob Khosravi ${ }^{4}$, Mohammad Amin Tabatabaiefar ${ }^{5}$ and Nader Mansour Samaei ${ }^{6}$

${ }^{1}$ Department of Biology, Science and Research Branch, Islamic Azad University, Tehran, Iran.

${ }^{2}$ Mazandaran University of Medical Sciences, Sari, Iran.

${ }^{3}$ Department of Endocrinology, School of Medicine, Golestan University of Medical Sciences, Gorgan, Iran.

${ }^{4}$ Faculty of Advanced Medical Technologies, Golestan University of Medical Sciences, Gorgan, Iran.

${ }^{5}$ Department of Medical Genetics, School of Medicine, Ahvaz Jundishapur University of Medical Sciences, Ahvaz, Iran.

${ }^{6}$ Biochemistry and Metabolic Disorders Research Center, Faculty of Advanced Medical Technologies, Golestan University of Medical Sciences, Gorgan, Iran.

\begin{abstract}
In various populations worldwide, common variants of the TCF7L2 (Transcription factor 7-like 2) gene are associated with the risk of type 2 diabetes mellitus (T2DM). The aim was to investigate the association between rs 12255372 (G/T) polymorphism in the TCF7L2 gene and T2DM in an Iranian population. 236 unrelated patients with T2DM, and 255 normoglycemic controls without diabetes were studied. The PCR-RFLP method was used for genotyping rs12255372 (G/T) polymorphism, and the SPSS version 18.0 for Windows for statistical analysis. The minor T allele of TCF7L2 rs12255372 was found to significantly increase the risk of T2DM, with an allelic odds ratio (OR) of 1.458 (95\% Cl 1.108-1.918, $p=0.007)$. A significant difference in TT genotype was observed between T2DM patients and normoglycemic controls (OR 2.038, 95\% Cl 1.147-3.623; $p=0.014)$. On assuming dominant and recessive models, ORs of $1.52[95 \% \mathrm{Cl}(1.05-2.21) \mathrm{p}=0.026)]$ and $1.74[95 \% \mathrm{Cl}(1.01-3.00) \mathrm{p}=0.043]$ were obtained, respectively, thereby implying that the co-dominant model would best fit the susceptible gene effect. This study further confirms the TCF7L2 gene as enhancing susceptibility to the development of T2DM.
\end{abstract}

Key words: TCF7L2 gene, rs12255372 variant, type 2 diabetes mellitus (T2DM), single nucleotide polymorphism (SNP).

Received: November 5, 2011; Accepted: January 24, 2012.

\section{Introduction}

Type 2 diabetes mellitus (T2DM) is a heterogeneous metabolic disorder arising from the interplay of genetic and environmental factors (Barroso, 2005). Diabetes and its associated complications pose a major health-care burden worldwide, presenting major challenges to patients well-being, health-care systems and national economies (Ramachandran et al., 2010). Although the prevalence of T2DM worldwide is about $6 \%$, it is likely to rise over the next decade, due to the increasing age of the population, and surge of obesity (Zimmet, et al., 2001). Accounting for $90 \sim 95 \%$ of populations with diabetes, T2DM is predicted to reach 300 million people worldwide by the year 2025

Send correspondence to Nader. M. Samaei. Biochemistry and Metabolic Disorders Research Center, Faculty of Advanced Medical Technologies, Golestan University of Medical Sciences, Shastkola Road, P.O. Box 4934174515, Gorgan, Iran. E-mail: samaei@goums.ac.ir.
(Zimmet et al., 2001; Grant et al., 2006;). There are significant geographic and racial differences in incidence, this ranging from 4.6 to $40 \%$ in the Middle East (Al-Nuaim, 1997; Abdella et al., 1998; Husseini et al., 2000; Al-Habori et al., 2004), $1.2 \%$ to $14.6 \%$ in Asia, and $1.3 \%$ to $14.5 \%$ in Iran (Azizi et al., 2003a,b).

The transcription factor 7-like 2 gene (TCF7L2), also known as TCF-4, is a nuclear receptor for CTNNB1 (previously known as $\beta$-catenin), which in turn mediates the canonical WNT signaling pathway (Polakis, 2000; Smith, 2007). Recent genome-wide association studies have dramatically increased knowledge on the genetic background of T2DM. Intronic variants of the TCF7L2 gene, besides having been set forth as possible genetic risk factors for T2DM, have also been associated with alterations in the function of beta cells among normoglycemic individuals (Bonetti et al., 2011). Current evidence presupposes that the predominant effect of TCF7L2 dysfunction on type 2 diabetes development may be mediated through the impair- 
ment of insulin secretion (Damcott et al., 2006; Florez et al., 2006; Saxena et al., 2006; Scott et al., 2006; Chandak et al., 2007). Grant and colleagues have reported the association of a common microsatellite (DG10S478) within intron 3 of TCF7L2 with T2DM. They showed that allele G of SNP rs12255372 is in strong linkage disequilibrium (LD) with allele 0 of DG10S478, as allele T of rs 12255372 is with other alleles of DG10S478 (Grant et al., 2006).

There are at least four well-studied polymorphic markers in the humanTCF7L2 gene, which are associated with T2DM, viz., rs7903146, rs7901695, rs12255372 and rs11196205. Most published epidemiological studies have placed emphasis on rs7903146 (C/T) and rs12255372 (G/T) variations (Luo et al., 2009; Tong et al., 2009), with the consequential association of rs 7903146 TCF7L2 polymorphism with T2DM (Amoli et al., 2010).

In this study, the aim was to investigate the association between the TCF7L2 rs12255372 variant and T2DM in an Iranian population. To our knowledge, this SNP has not been previously tested in the Iranian population.

\section{Subjects and Method}

\section{Subjects}

The studied population comprised 236 unrelated T2DM patients and 255 normoglycemic controls without diabetes. The T2DM patients were recruited from the Gorgan Clinic of Diabetes, Golestan University of Medical Sciences, north Iran. The normoglycemic controls, recruited from the same area, were age-matched with the case population. T2DM-patient diagnosis, based on the standard criteria (American Diabetes Association, 2004), with fasting plasma glucose $\geq 126 \mathrm{mg} / \mathrm{dL}$, 2-h plasma glucose $\geq$ $200 \mathrm{mg} / \mathrm{dL}$ during an oral glucose tolerance test. Written informed consent was obtained from each subject. Patients with the age-of-onset $<37$ years were excluded. All those selected for this study were of Fars origin.

\section{Clinical characteristics}

Anthropometric measurements of weight, height and waist-circumference were obtained by standardized techniques. The body mass index (BMI) was calculated as the weight in kilograms divided by the square of the height in meters. $\mathrm{HbA} 1 \mathrm{c}$ levels were defined by using turbidometric inhibition immunoassaying (Tina Quant, Roche, Basel, Switzerland).

BMI, waist circumference and $\mathrm{HbA1c}$ were measured in T2DM patients and normoglycemic controls.

\section{DNA extraction and genotyping}

Genomic DNA was extracted from peripheral blood leukocytes using the phenol/chloroform procedure. The study was approved by the Ethics committee of Golestan University of Medical Sciences (No: 1090). The rs12255372 polymorphism was genotyped using the PCR-
RFLP method. Briefly, the region was amplified with the following primers: Forward 5'- CTG GAA ACT AAG GCG TGA GG -3'; Reverse 5'- GGG TCG ATG TTG TTG AGC TT $-3^{\prime}$. The PCR cycles were as follows: $5 \mathrm{~min}$ at $94{ }^{\circ} \mathrm{C}$, followed by 35 cycles of $30 \mathrm{~s}$ at $94{ }^{\circ} \mathrm{C}, 30$ s at $54{ }^{\circ} \mathrm{C}$ and $30 \mathrm{~s}$ at $72{ }^{\circ} \mathrm{C}$. Final extension was for $10 \mathrm{~min}$ at $72{ }^{\circ} \mathrm{C}$. Subsequently, $10 \mu \mathrm{L}$ of the $346 \mathrm{bp}$ amplified product was digested with the TsaI (Tsp509I) restriction enzyme (Fermentas, EU) for $3 \mathrm{~h}$ at $65^{\circ} \mathrm{C}$. After treatment with restriction enzymes, amplicons were subjected to $3.5 \%$ agarose gel electrophoresis and stained with ethidium bromide. The studied region usually has two restriction sites, the $G \rightarrow T$ allele change creating a new one. Some genotyping results were validated by direct sequencing.

\section{Statistical analysis}

Data analysis was with SPSS Statistical software (version 18, SPSS, Chicago, IL, USA). A $P$ value of $<0.05$ was considered as significant. Mean \pm SD and relative frequency were used for quantitative and qualitative traits, respectively. The SHAPIRO-WILK test was applied to diabetic and normoglycemic subjects, to compare normality of quantitative traits in both groups, the mean of these traits being subsequently compared by t-testing. The association of SNPs with T2DM in matched case-control subjects was tested using $\chi^{2}$ analysis, as well as the calculation of Odds ratios (ORs), with 95\% confidence intervals (CIs).

\section{Results}

A case-control association study was undertaken, comprising $236 \mathrm{~T} 2 \mathrm{DM}$ patients and 255 normoglycemic controls, all over 37 years-of-age. 35 subjects (20 normoglycemic controls and 15 T2DM patients) were excluded, through unavailability of individual genomic DNA, thus leaving $221 \mathrm{~T} 2 \mathrm{DM}$ patients and 235 normoglycemic controls for genotyping. Genotype frequencies did not differ from the expected Hardy-Weinberg ratios.

The minor $\mathrm{T}$ allele of the TCF7L2 rs 12255372 was found to significantly increase T2DM risk, with an allelic odds ratio (OR) of 1.458 (95\% CI 1.108-1.918, $\mathrm{p}=0.007$ ) in the population under study. $\mathrm{T}$ allele frequency was $38.7 \%$ in $\mathrm{T} 2 \mathrm{DM}$ patients and $30.2 \%$ in normoglycemic controls (Table 1).

A comparison of genotype frequencies in T2DM patients and normoglycemic controls showed a significant difference in the frequency of the TT genotype (OR 2.038, $95 \%$ CI 1.147-3.623; $p=0.014$ ), although not so in the GG and GT genotypes (Table 1).

To investigate which model would fit the effect of TCF7L2 rs 12255372, dominant and recessive models were considered. In the dominant model (GG vs. TT and GT), the genotype frequencies were compared between the T2DM and control groups and a significant association with T2DM was observed (OR 1.52, 95\% CI (1.05-2.21) 
$\mathrm{p}=0.026$ ). Assuming the recessive model (GG and GT vs. $\mathrm{TT}$ ), a significant association was also found (OR 1.74, 95\% CI (1.01-3.00) $\mathrm{p}=0.043)$. Thus, the highest risk was observed under the co-dominant model (OR 2.038, 95\% CI (1.147-3.623) $\mathrm{p}=0.014)$ (Table 1).

Based on rs12255372 (GT) genotypes, the clinical and biochemical characteristics of the T2DM patients and normoglycemic individuals were stratified. With the exception of waist circumference, which was significantly higher in $\mathrm{G}$ allele homozygotes $(\mathrm{p}=0.002)$, no association was found between this variant and either age, BMI or HbA1c in T2DM patients (Table 2). Comparative analyses of normoglycemic controls and rs12255372 (G/T) genotypes also revealed no association of clinical characteristics with the genotype (data not shown).

\section{Discussion}

In this study, the aim was to explore the association of TCF7L2 rs12255372 polymorphism with Type 2 diabetes (T2DM) in an Iranian population. We found that the minor $\mathrm{T}$ allele of TCF7L2 rs12255372 significantly increases T2DM risk, with an allelic odds ratio (OR) of $1.458(95 \%$ CI $1.108-1.918, \mathrm{p}=0.007$ ) (Table 1). Although the strongest association with T2DM risk in most reported studies is with rs7903146, some studies have shown a stronger association with rs12255372 (Scott et al., 2006; Chandak et al., 2007; Hayashi et al., 2007; Wang et al., 2007; Saadi et al., 2008).

However, no association between a TCF7L2 rs12255372 variant and T2DM has been reported in Chinese, Arabic and Pima Indian populations (Chang et al., 2007; Guo et al., 2007; Alsmadi et al., 2008;). Furthermore, a modest association of TCF7L2 rs12255372 with T2DM was shown in an African-American population (Sale et al., 2007). The underlying mechanisms, by which genetic variation within the intron of the TCF $7 L 2$ gene confers susceptibility to type 2 diabetes, remain to be elucidated. Genetic variations near the 3' end of the TCF7L2 gene may affect the action of TCF7L2, through the regulation of alternative splicing (Chang et al., 2007).

Frequency of the minor $\mathrm{T}$ allele in the normoglycemic controls was found to be $30.2 \%$, thus, although consistent with Palestinian, Amish and French populations (29.3, 29, and 30\%, respectively) (Cauchi et al., 2006; Damcott et al., 2006; Ereqat et al., 2010), quite different from that reported in a Chinese population (3\%) (Ren et al., 2008). The frequency of the TT genotype carrying the two minor alleles (risk alleles) was significantly different in T2DM patients compared to normoglycemic controls, thereby implying a possible gene dosage effect. However, although the frequency of the GT genotype was higher in the T2DM patients compared to normoglycemic controls, no significant difference was observed between GT genotypes and T2DM.

To determine whether there is any interaction between rs12255372 (G/T) genotypes and clinical and biochemical characteristics, the association between genotypes and covariates in T2DM patients and normoglycemic controls was studied separately. Although no association was found between the variant and age, BMI and $\mathrm{HbA} 1 \mathrm{c}$ in T2DM patients, in an earlier study of Emirati subjects (Saadi et al., 2008), waist circumference was found to be significantly higher in $\mathrm{G}$ allele homozygotes.

The study proved the rs 12255372 variant of the TCF7L2 gene to be associated with T2DM in the Iranian population, in contrast with previous reports on Chinese,

Table 1 - The TCF7L2 rs12255372 polymorphism allele and genotype frequencies in T2DM patients and normoglycemic controls.

\begin{tabular}{lcccc}
\hline Genotype & normoglycemic controls $(\mathrm{n}=235)$ & $\mathrm{T}_{2} \mathrm{DM}^{*}$ patients $(\mathrm{n}=221)$ & OR $(95 \% \mathrm{CI})$ & $\mathrm{p}^{\mathrm{value}}{ }^{\dagger}$ \\
\hline GG (\%) & $118(50.2)$ & $88(39.8)$ & - & - \\
GT (\%) & $92(39.1)$ & $95(42.9)$ & $1.385(0.930-2.061)$ & 0.109 \\
TT (\%) & $25(10.6)$ & $38(17.1)$ & $2.038(1.147-3.623)$ & 0.014 \\
G allele (\%) & $328(69.8)$ & $271(61.3)$ & - & - \\
T allele (\%) & $142(30.2)$ & $171(38.7)$ & $1.458(1.108-1.918)$ & 0.007 \\
\hline
\end{tabular}

*Type 2 diabetes mellitus. ${ }^{\dagger} \mathrm{A} p$ value of $<0.05$ was considered as significant.

Table 2 - Clinical characteristics of the T2DMM subjects stratified by rs12255372 (G/T) genotypes.

\begin{tabular}{lcccc}
\hline Variable & GG & GT & TT & p value \\
\hline Age (years) & $52.40 \pm 7.32$ & $51.29 \pm 10.68$ & $51.61 \pm 11.68$ & 0.741 \\
Waist circumference $(\mathrm{cm})$ & $104.54 \pm 13.29$ & $97.87 \pm 11.92$ & $99.68 \pm 10.99$ & $\mathbf{0 . 0 0 2}$ \\
BMI $\left(\mathrm{kg} / \mathrm{m}^{2}\right)$ & $29.82 \pm 5.10$ & $29.15 \pm 4.75$ & $28.88 \pm 5.51$ & 0.34 \\
HbA1C & $8.75 \pm 1.93$ & $9.00 \pm 2.19$ & $8.73 \pm 2.05$ & 0.656 \\
\hline
\end{tabular}


Arab and Pima Indian populations. According to the conclusions divulged in a recently published meta-analysis (Tong et al., 2009), the magnitudes of this association are moderate. TT homozygous variants would approximately cause a 1.9-fold increase in T2MD as concluded by results of many studies, a value that is lesser but still close to our own result $(\mathrm{OR}=2.038)$. A possible explanation for this incongruity could be differences in ethnic background, or the effects of environmental factors, such as life-style. Further studies are required to clarify the exact mechanism of its effect.

\section{Acknowledgments}

This research project was supported by the Golestan University of Medical Sciences. We wish to thank all those who participated in this study. We are also grateful $\mathrm{Mr}$ Naser Behnampour for his invaluable comments.

\section{References}

Abdella N, Al Arouj M, Al Nakhi A, Al Assoussi A and Moussa M(1998) Non-insulin-dependent diabetes in Kuwait: Prevalence rates and associated risk factors. Diabetes Res Clin Pract 42:187-196.

American Diabetes Associatgion (2004) Standards of medical care in diabetes. Diabetes Care 27 Suppl 1:S15-S35.

Al-Habori M, Al-Mamari M and Al-Meeri A (2004) Type II Diabetes Mellitus and impaired glucose tolerance in Yemen: Prevalence, associated metabolic changes and risk factors. Diabetes Res Clin Pract 65:275-281.

Al-Nuaim AR (1997) Prevalence of glucose intolerance in urban and rural communities in Saudi Arabia. Diabet Med 14:595-602.

Alsmadi O, Al-Rubeaan K, Mohamed G, Alkayal F, Al-Saud H, Al-Saud NA, Al-Daghri N, Mohammad S and Meyer BF (2008) Weak or no association of TCF7L2 variants with Type 2 diabetes risk in an Arab population. BMC Med Genet 9:e72.

Amoli MM, Amiri P, Tavakkoly-Bazzaz J, Charmchi E, Hafeziyeh J, Keramatipour M, Abiri M, Ranjbar SH and Larijani B (2010) Replication of TCF7L2 rs7903146 association with type 2 diabetes in an Iranian population. Genet Mol Biol 33:449-451.

Azizi F, Gouya MM, Vazirian P, Dolatshahi P and Habibian S (2003a) The diabetes prevention and control programme of the Islamic Republic of Iran. East Mediterr Health J 9:11141121.

Azizi F, Guoya MM, Vazirian P, Dolatshati P and Habbibian S (2003b) Screening for type 2 diabetes in the Iranian national programme: A preliminary report. East Mediterr Health J 9:1122-1127.

Barroso I (2005) Genetics of Type 2 diabetes. Diabet Med 22:517-535.

Bonetti S, Trombetta M, Malerba G, Boselli L, Trabetti E, Muggeo M, Stoico V, Negri C, Pignatti PF, Bonora E, et al. (2011) Variants and haplotypes of TCF7L2 are associated with beta-cell function in patients with newly diagnosed type 2 diabetes: The Verona Newly Diagnosed Type 2 Dia- betes Study (VNDS) 1. J Clin Endocrinol Metab 96:E389393.

Cauchi S, Meyre D, Dina C, Choquet H, Samson C, Gallina S, Balkau B, Charpentier G, Pattou F, Stetsyuk V, et al. (2006) Transcription factor TCF7L2 genetic study in the French population: Expression in human beta-cells and adipose tissue and strong association with type 2 diabetes. Diabetes 55:2903-2908.

Chandak GR, Janipalli CS, Bhaskar S, Kulkarni SR, Mohankrishna P, Hattersley AT, Frayling TM and Yajnik CS (2007) Common variants in the TCF7L2 gene are strongly associated with type 2 diabetes mellitus in the Indian population. Diabetologia 50:63-67.

Chang YC, Chang TJ, Jiang YD, Kuo SS, Lee KC, Chiu KC and Chuang LM (2007) Association study of the genetic polymorphisms of the transcription factor 7-like 2 (TCF7L2) gene and type 2 diabetes in the Chinese population. Diabetes 56:2631-2637.

Damcott CM, Pollin TI, Reinhart LJ, Ott SH, Shen H, Silver KD, Mitchell BD and Shuldiner AR (2006) Polymorphisms in the transcription factor 7-like 2 (TCF7L2) gene are associated with type 2 diabetes in the Amish: Replication and evidence for a role in both insulin secretion and insulin resistance. Diabetes 55:2654-2659.

Ereqat S, Nasereddin A, Cauchi S, Azmi K, Abdeen Z and Amin $R$ (2010) Association of a common variant in TCF7L2 gene with type 2 diabetes mellitus in the Palestinian population. Acta Diabetol 47:195-198.

Florez JC, Jablonski KA, Bayley N, Pollin TI, de Bakker PI, Shuldiner AR, Knowler WC, Nathan DM and Altshuler D (2006) TCF7L2 polymorphisms and progression to diabetes in the Diabetes Prevention Program. N Engl J Med 355:241-250.

Grant SF, Thorleifsson G, Reynisdottir I, Benediktsson R, Manolescu A, Sainz J, Helgason A, Stefansson H, Emilsson V, Helgadottir A, et al. (2006) Variant of transcription factor 7-like 2 (TCF7L2) gene confers risk of type 2 diabetes. Nat Genet 38:320-323.

Guo T, Hanson RL, Traurig M, Muller YL, Ma L, Mack J, Kobes S, Knowler WC, Bogardus C and Baier LJ (2007) TCF7L2 is not a major susceptibility gene for type 2 diabetes in Pima Indians: Analysis of 3,501 individuals. Diabetes 56:30823088 .

Hayashi T, Iwamoto Y, Kaku K, Hirose H and Maeda S (2007) Replication study for the association of TCF7L2 with susceptibility to type 2 diabetes in a Japanese population. Diabetologia 50:980-984.

Husseini A, Abdul-Rahim H, Awartani F, Giacaman R, Jervell J and Bjertness E (2000) Type 2 diabetes mellitus, impaired glucose tolerance and associated factors in a rural Palestinian village. Diabet Med 17:746-748.

Luo Y, Wang H, Han X, Ren Q, Wang F, Zhang X, Sun X, Zhou X and Ji L (2009) Meta-analysis of the association between SNPs in TCF7L2 and type 2 diabetes in East Asian population. Diabetes Res Clin Pract 85:139-146.

Polakis P (2000) Wnt signaling and cancer. Genes Dev 14:18371851.

Ramachandran A, Ma RC and Snehalatha C (2010) Diabetes in Asia. Lancet 375:408-418.

Ren Q, Han XY, Wang F, Zhang XY, Han LC, Luo YY, Zhou XH and Ji LN (2008) Exon sequencing and association analysis 
of polymorphisms in TCF7L2 with type 2 diabetes in a Chinese population. Diabetologia 51:1146-1152.

Saadi H, Nagelkerke N, Carruthers SG, Benedict S, Abdulkhalek S, Reed R, Lukic M and Nicholls MG (2008) Association of TCF7L2 polymorphism with diabetes mellitus, metabolic syndrome, and markers of beta cell function and insulin resistance in a population-based sample of Emirati subjects. Diabetes Res Clin Pract 80:392-8.

Sale MM, Smith SG, Mychaleckyj JC, Keene KL, Langefeld CD, Leak TS, Hicks PJ, Bowden DW, Rich SS and Freedman BI (2007) Variants of the transcription factor 7-like 2 (TCF7L2) gene are associated with type 2 diabetes in an African-American population enriched for nephropathy. Diabetes $56: 2638-2642$.

Saxena R, Gianniny L, Burtt NP, Lyssenko V, Giuducci C, Sjogren $\mathrm{M}$, Florez JC, Almgren P, Isomaa B, Orho-Melander $\mathrm{M}$, et al. (2006) Common single nucleotide polymorphisms in TCF7L2 are reproducibly associated with type 2 diabetes and reduce the insulin response to glucose in nondiabetic individuals. Diabetes 55:2890-2895.

Scott LJ, Bonnycastle LL, Willer CJ, Sprau AG, Jackson AU, Narisu N, Duren WL, Chines PS, Stringham HM, Erdos
MR, et al. (2006) Association of transcription factor 7-like 2 (TCF7L2) variants with type 2 diabetes in a Finnish sample. Diabetes 55:2649-2653.

Smith U (2007) TCF7L2 and type 2 diabetes-we WNT to know. Diabetologia 50:5-7.

Tong Y, Lin Y, Zhang Y, Yang J, Liu H and Zhang B (2009) Association between TCF7L2 gene polymorphisms and susceptibility to type 2 diabetes mellitus: A large Human Genome Epidemiology (HuGE) review and meta-analysis. BMC Med Genet 10:e15.

Wang J, Kuusisto J, Vanttinen M, Kuulasmaa T, Lindstrom J, Tuomilehto J, Uusitupa M and Laakso M (2007) Variants of transcription factor 7-like 2 (TCF7L2) gene predict conversion to type 2 diabetes in the Finnish Diabetes Prevention Study and are associated with impaired glucose regulation and impaired insulin secretion. Diabetologia 50:1192-1200.

Zimmet P, Alberti KG and Shaw J (2001) Global and societal implications of the diabetes epidemic. Nature 414:782-787.

Associate Editor: Mara Hutz

License information: This is an open-access article distributed under the terms of the Creative Commons Attribution License, which permits unrestricted use, distribution, and reproduction in any medium, provided the original work is properly cited. 